\title{
Perceived Neighborhood Environment Associated with Sarcopenia in Urban-Dwelling Older Adults: The Korean Frailty and Aging Cohort Study (KFACS)
}

\author{
Yuri Seo ${ }^{1}$, Miji Kim ${ }^{2, *} \mathbb{D}$, Hyungeun Shin ${ }^{1}$ and Changwon Won ${ }^{3, *(\mathbb{D}}$ \\ 1 Department of Biomedical Science and Technology, Graduate School, Kyung Hee University, \\ Seoul 02447, Korea; dkddkkd55@naver.com (Y.S.); she9310@hanmail.net (H.S.) \\ 2 Department of Biomedical Science and Technology, East-West Medical Research Institute, \\ College of Medicine, Kyung Hee University, Seoul 02447, Korea \\ 3 Elderly Frailty Research Center, Department of Family Medicine, College of Medicine, Kyung Hee University, \\ Seoul 02447, Korea \\ * Correspondence: mijiak@khu.ac.kr (M.K.); chunwon62@naver.com (C.W.); \\ Tel.: +82-2-958-2840 (M.K.); +82-2-958-8700 (C.W.); Fax: +82-2-958-2836 (M.K.); +82-2-958-8699 (C.W.)
}

Citation: Seo, Y.; Kim, M.; Shin, H.; Won, C. Perceived Neighborhood Environment Associated with Sarcopenia in Urban-Dwelling Older Adults: The Korean Frailty and Aging Cohort Study (KFACS). Int. J. Environ. Res. Public Health 2021, 18, 6292. https:// doi.org/10.3390/ijerph18126292

Academic Editors: Martina Amanzio, Giuseppina Elena Cipriani and Massimo Bartoli

Received: 26 April 2021

Accepted: 9 June 2021

Published: 10 June 2021

Publisher's Note: MDPI stays neutral with regard to jurisdictional claims in published maps and institutional affiliations.

Copyright: (c) 2021 by the authors. Licensee MDPI, Basel, Switzerland. This article is an open access article distributed under the terms and conditions of the Creative Commons Attribution (CC BY) license (https:// creativecommons.org/licenses/by/ $4.0 /)$.
Abstract: Sarcopenia is associated with adverse health outcomes among older individuals. However, little is known about its association with neighborhood environmental factors. We explored the relationship between sarcopenia and perceived neighborhood environmental factors among community-dwelling older adults aged 70-84 years. We analyzed 1778 participants (mean age of $75.9 \pm 3.8$ years; $54.0 \%$ women) who lived in urban areas and underwent dual-energy X-ray absorptiometry from the Korean Frailty and Aging Cohort Study. Sarcopenia was defined according to the Asian Working Group for Sarcopenia 2019 definition. Perceived neighborhood environmental factors were assessed using the Environmental Module of the International Physical Activity Questionnaire (IPAQ-E). In the multivariate analysis, compared to the fifth quintile of the IPAQ-E score, the odds ratios (ORs) and 95\% confidence intervals (CIs) for sarcopenia in the first, second, third, and fourth quintiles were 2.13 (1.40-3.24), 1.72 (1.12-2.64), 1.75 (1.15-2.66), and 1.62 (106-247), respectively. These neighborhood environmental characteristics were linked with an increased likelihood of sarcopenia: no public transportation access $(\mathrm{OR}=2.04 ; 95 \% \mathrm{CI}=1.19-3.48)$, poor recreational facilities access $(\mathrm{OR}=1.39 ; 95 \% \mathrm{CI}=1.01-1.90)$, absence of destination $(\mathrm{OR}=1.53 ; 95 \% \mathrm{CI}=1.06-2.20)$, many hill hazards $(\mathrm{OR}=1.36 ; 95 \% \mathrm{CI}=1.03-1.78)$, and lack of traffic safety $(\mathrm{OR}=1.35 ; 95 \% \mathrm{CI}=1.02-1.78)$. Thus, better neighborhood environmental strategies may help prevent sarcopenia among urban-dwelling older adults.

Keywords: environment; sarcopenia; cohort study; aging

\section{Introduction}

Sarcopenia is related to adverse health outcomes such as falls, functional decline, frailty, and mortality [1], which cause personal, social, and economic burden among older adults [2,3]. The prevalence of sarcopenia is around $10 \%$ in community-dwelling older adults aged $\geq 60$ years, and its incidence may increase with every one-year increase in age [4]. Therefore, it is important to identify the risk factors that affect the development of sarcopenia. Risk factors for sarcopenia include physical inactivity, poor nutritional status, inflammation, oxidative stress, and chronic diseases [1,5]. Most of these risk factors can be prevented through lifestyle changes; however, environmental support is needed to maintain or achieve a healthy lifestyle [6].

The World Health Organization (WHO) emphasized the role of the physical and social neighborhood environment for "healthy and active aging" in older adults in its guidelines of global age-friendly cities [7,8]. Many studies have previously reported that a poor neighborhood environment is associated with adverse health outcomes, including falls [9], 
disability [10], frailty [11,12], and mortality [13] all of which are known to be related to sarcopenia. Previous studies have reported that the neighborhood environment promotes healthy lifestyle habits, such as increased physical and social activity [13-15] and better dietary choices in older adults $[16,17]$. Therefore, the neighborhood environment may have implications in the prevention of sarcopenia because it provides older adults opportunities to participate in physical and social activities.

A longitudinal study found that neighborhood environmental factors that were objectively measured using geographic information systems were related to declines in muscle mass and grip strength in older adults [18]. Another study confirmed the association between neighborhood walkability using the Walk Score website and risk of sarcopenia [16]. However, these studies did not analyze various neighborhood environmental factors, including the walking environment, aesthetics, and safety, etc. In addition, we previously identified the relationship between physical frailty and the perceived neighborhood environment [12]. As a result of the study, physical frailty was related to the IPAQ-E total score, access to destinations, and neighborhood safety factors [12]. Sarcopenia shares common risk factors with physical frailty [5], it may be related to various neighborhood environmental factors. Therefore, using a structured questionnaire, we aimed to investigate the relationship between perceived neighborhood environment and sarcopenia, as diagnosed using the Asian Working Group for Sarcopenia (AWGS) criteria among urban-dwelling older adults.

\section{Materials and Methods}

\subsection{Study Design and Participants}

This study analyzed baseline data obtained from the Korean Frailty and Aging Cohort Study (KFACS). The KFACS is a nationwide, longitudinal cohort study of older adults aged 70-84 years, and the baseline survey was conducted from 2016 to 2017. The participants were recruited from age- and sex-stratified community residents of 10 centers in rural, sub-urban, and urban areas; the ratio of the age groups 70-74 years, 75-79 years, and 80-84 years was 6:5:4, and the male:female sex ratio was 1:1 [19]. A total of 3014 individuals participated in the baseline KFACS, and participants who were living in rural areas $(n=909)$ and had missing data regarding residence $(n=16)$ were excluded. Consequently, only participants who were living in urban areas and underwent dual-energy $\mathrm{X}$-ray absorptiometry (DXA) for appendicular skeletal muscle mass were included $(n=1930)$. The exclusion criteria were as follows: (i) dependence on any of the five basic activities of daily living (ADL; $n=34$ ); (ii) clinical diagnosis of dementia $(n=3)$; (iii) history of hemiplegia $(n=5)$; and (iv) severe cognitive impairment, which was defined as a score of $<10$ in the Mini-Mental State Examination (MMSE; $n=3$ ). A total of 107 participants were excluded for having missing data regarding the IPAQ-E scores $(n=92)$, education years and social security recipient $(n=10)$, Mini Nutritional Assessment (MNA) scores $(n=1)$, low physical activity $(n=1)$, and organizational participation $(n=3)$. The final sample comprised 1778 participants (Figure 1). This study received ethical approval for the KFACS protocol from the Clinical Research Ethics Committee of Kyung Hee University (Institutional Review Board [IRB] number: 2015-12-103). The present study was exempt from requiring approval by the IRB of the Clinical Research Ethics Committee of Kyung Hee University Medical Center (IRB number: 2021-01-032). 


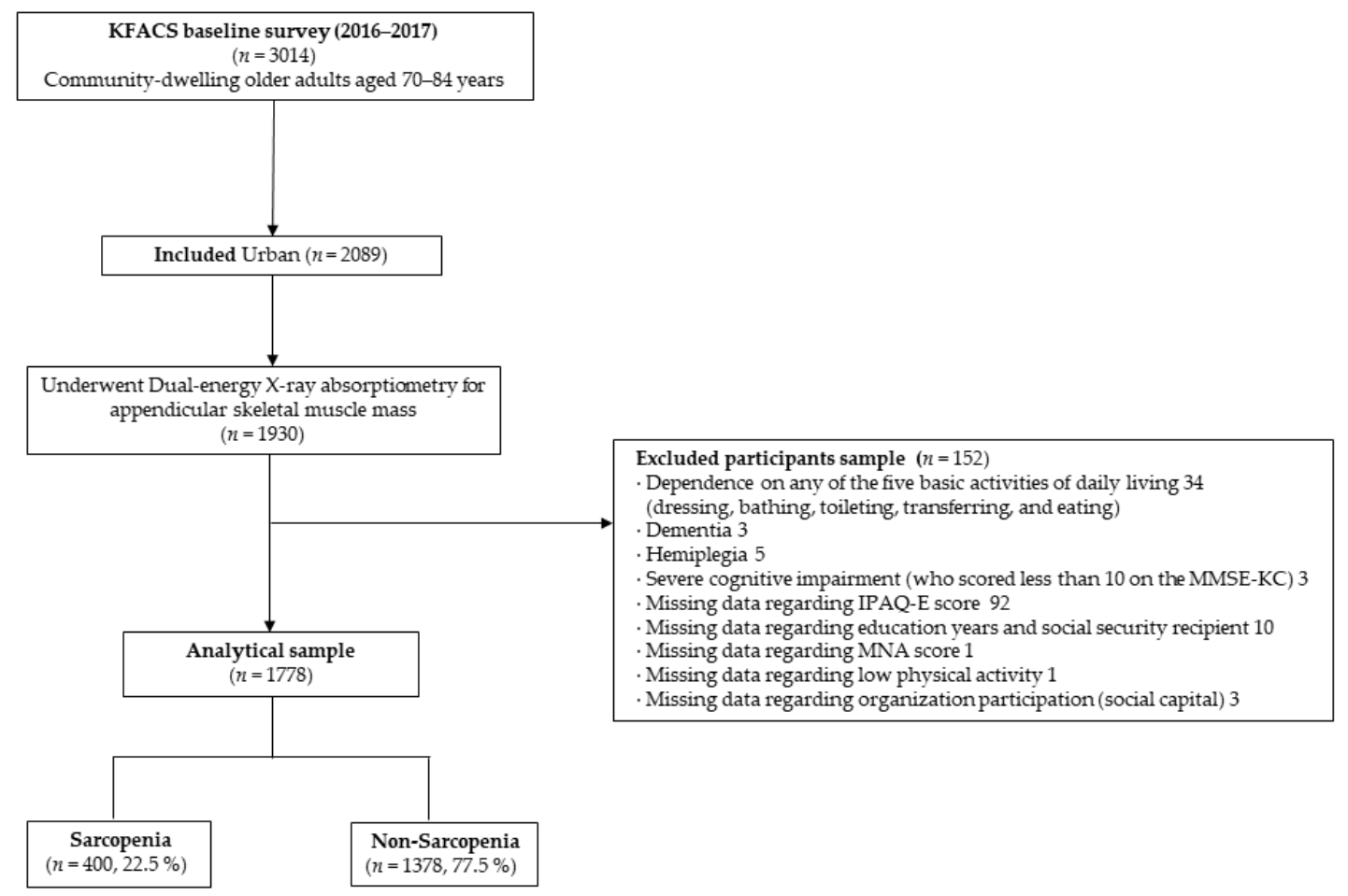

Figure 1. Flow chart of the study population.

\subsection{Perceived Neighborhood Environment Assessment}

Perceived neighborhood environment was assessed using the IPAQ-E (self-report format) [20]. The IPAQ-E is a tool developed to evaluate perceived environmental factors that affect physical activity and has been used in many countries [21-23]. The reliability of the questionnaire has been verified [24]. Neighborhood environment in the IPAQ-E is defined as a 10-15-min walk from the home, which includes environmental characteristics consisting of 17 items regarding both physical and social environmental factors, and the items are categorized into seven components [20]: (i) residential density (one item: type of housing); (ii) access to destinations (five items: perceived range or accessibility to the destination by walk, which include shops, public transports, recreational facilities, destination [bank, hospital], and hill hazards); (iii) neighborhood infrastructure (four items: perceived safety for walking and cycling, which include presence and maintenance of sidewalks and bike lanes); (iv) neighborhood safety (four items: perceived safety for crime and traffic, which include crime safety at night and during the day, traffic safety, and traffic safety for bicyclists); (v) social environment (one item: seeing people being active); (vi) aesthetic qualities (one item: perceived attractiveness of landscape and pleasantness of places); and (vii) street connectivity (one item: connectivity of streets) [20]. Appendix A provides the 17 items and the methods for scoring them. Each item has a possible score from 1 to 4 , except for "type of housing," which is scored from 0 to 1 ; the total possible score is from 16 to 65 , with higher scores indicating better perceived neighborhood environment $[12,25]$. In addition, the dichotomized variable is coded as " 0 " for 1-2 points and "1" for 3-4 points [12].

\subsection{Definition of Sarcopenia}

Sarcopenia was defined as low muscle mass (appendicular skeletal muscle mass [ASM] index of $<7.0 \mathrm{~kg} / \mathrm{m}^{2}$ in men and $<5.4 \mathrm{~kg} / \mathrm{m}^{2}$ in women) combined with low muscle strength (hand grip strength [HGS] of $<28 \mathrm{~kg}$ in men and $<18 \mathrm{~kg}$ in women) or low physical performance (defined for both men and women as a low result in at least one of the three physical performance measures: usual gait speed of $<1.0 \mathrm{~m} / \mathrm{s}$; sit-to-stand test score of $\geq 12$ s; or low Short Physical Performance Battery [SPPB] score of $\leq 9$ ), according to the 
criteria established by the AWGS 2019 consensus [26]. Three components for evaluating sarcopenia were measured as follows: (i) ASM was assessed using DXA (Hologic DXA, Hologic Inc., Bedford, MA, USA; Lunar, GE Healthcare, Madison, WI, USA) [27], which measures the sum of the lean mass of the right and left arms and legs; (ii) HGS was measured twice in each hand while in a standing position, using a digital hand grip dynamometer (T.K.K.5401; Takei Scientific Instruments Co, Ltd, Tokyo, Japan), and the highest value was used for the analysis [28]; and (iii) low physical performance was assessed using the gait speed, sit-to-stand test score, and SPPB score. The gait speed was assessed over $4 \mathrm{~m}$ using an automatic gait speed meter (Dynamic Physiology, Daejeon, Korea), with acceleration and deceleration phases of $1.5 \mathrm{~m}$ each. The test was repeated twice, and the average of the two trials was used for the analysis. The sit-to-stand test measured the time it took to get up from and sit on a chair for a total of five times as quickly as possible, with arms across their chest. The time required to finish five repetitions was used for the analysis [29]. The SPPB independently investigated three items: balance test (side-by-side stance, semi-tandem stance, and tandem stance), usual gait speed, and five-times sit-to-stand test. Each item of the SPPB has a possible score of $0-4$, with the total possible score ranging from 0 to 12 [30].

\subsection{Other Measurements}

\subsubsection{Sociodemographic Variables}

Demographic characteristics included residence, age, sex, years of education, living conditions, marital status, and social security recipient. ADL was assessed using the Korean Activities of Daily Living (KADL) scale [31].

\subsubsection{Health-Related and Lifestyle Variables}

Health-related and lifestyle factors included body mass index (BMI), medical history, smoking status, and alcohol consumption ( $\geq 2-3$ times/week). Low physical activity was defined as $<494.65 \mathrm{kcal}$ for men and $<283.50 \mathrm{kcal}$ for women (as assessed by the International Physical Activity Questionnaire), with these values corresponding to the lowest $20 \%$ of the total consumed energy established among the general population of Korean older adults [19]. Nutritional status was evaluated using the Korean version of the short-form Mini Nutritional Assessment (MNA-SF) [32]. The following comorbidities were recorded: those related to the circulatory system (hypertension, dyslipidemia, myocardial infarction, congestive heart failure, angina pectoris, peripheral vascular disease, and cerebrovascular disease), those related to the musculoskeletal system and connective tissue (osteoarthritis, rheumatoid arthritis, and osteoporosis), and those related to the respiratory system (asthma and chronic obstructive pulmonary disease), according to doctors' diagnoses as self-reported by the participants.

\subsubsection{Psychosocial or Social Variables}

Psychosocial and social variables, including self-perceived health, were assessed using the EuroQoL five-dimension (EQ-5D) scale [33], and the answers were classified as good or poor. Depressive symptoms were evaluated using the Korean version of the Short Form Geriatric Depression Scale (SGDS-K) [34]. Cognitive function was determined using the Mini-Mental State Examination (MMSE) [35]. Participation in social meetings was classified as yes or no.

\subsection{Statistical Analysis}

Descriptive statistics were used to analyze the participants' characteristics. Independent $t$-tests and chi-square tests were used to describe the differences between the non-sarcopenia and sarcopenia groups. The characterization comparisons of the sarcopenia group were analyzed using univariate logistic regression and described as odds ratios (ORs) using 95\% confidence intervals (CIs). Multivariate logistic regression analyses were used to ascertain the association between sarcopenia and neighborhood environmental factors 
in urban areas. The following covariates were included in the logistic regression models: Model 1, adjusted for sociodemographic variables (age, sex, education, living alone, marital status, and social security recipient) and DXA equipment used; Model 2, further adjusted for health-related and lifestyle variables (smoking status, alcohol consumption, number of comorbidities, nutritional status, low physical activity, and BMI); Model 3, further adjusted for psychosocial variables (depressive symptoms and cognitive function); and Model 4, further adjusted for social variables (participation in social meetings). Moreover, we used logistic regression to evaluate the association between sarcopenia and the IPAQ-E score quintiles, controlling for sociodemographic variables and DXA equipment used, healthrelated and lifestyle variables, psychosocial variables, and social variables. We used the relative risk (RR) for sarcopenia related to neighborhood environmental risk factors. In addition, estimates of the attributable risk (AR) and population AR (PAR) were calculated to identify the most significant neighborhood environmental factors contributing to sarcopenia. All the statistical analyses were performed using the SPSS software (ver. 25.0; IBM Corp., Armonk, NY, USA), with statistical significance set at $p<0.05$.

\section{Results}

\subsection{Characteristics of the Study Population}

The characteristics of participants with and without sarcopenia are shown in Table 1. Of the 1778 older adults ( $54.0 \%$ women, mean age of 75.9 years), $400(22.5 \%)$ had sarcopenia. Participants with sarcopenia were more likely to be older $(p<0.001)$ and women $(p=0.006)$. Regarding the health-related factors, the sarcopenia group had a higher smoking rate, higher prevalence of diabetes and osteoporosis $(p<0.05)$. Moreover, the sarcopenia group had lower physical activity levels, poorer nutritional status, a lower BMI, and took more medications (all $p<0.001$ ). Compared with those without sarcopenia, those with sarcopenia were more likely to perceive their health as poorer $(p<0.001)$, have more depressive symptoms $(p<0.001)$, and have worse cognitive function $(p=0.001)$. Additionally, those with sarcopenia seemed to have lower social participation levels $(p<0.05)$. There was a significant difference between the sarcopenia and non-sarcopenia groups regarding the HGS, gait speed, five-times sit-to-stand test score, SPPB score, and skeletal muscle mass index (all $p<0.001)$.

Table 1. Characteristics of participants in the non-sarcopenia and sarcopenia groups.

\begin{tabular}{|c|c|c|c|c|c|c|c|c|c|c|c|c|}
\hline \multirow{2}{*}{$\begin{array}{c}\text { Variables } \\
\text { Sociodemographic factors }\end{array}$} & \multicolumn{3}{|c|}{ Overall $(n=1778)$} & \multicolumn{3}{|c|}{$\begin{array}{l}\text { Non-Sarcopenia Group } \\
\qquad(n=1378)\end{array}$} & \multicolumn{3}{|c|}{$\begin{array}{l}\text { Sarcopenia Group } \\
\quad(n=400)\end{array}$} & $p$-Value ${ }^{\dagger}$ & OR & $(95 \%$ CI $) \ddagger$ \\
\hline & & & & & & & & & & & & \\
\hline Age (years) & 75.9 & \pm & 3.8 & 75.5 & \pm & 3.7 & 77.2 & \pm & 3.8 & $<0.001$ & 1.12 & $(1.09-1.16) * * *$ \\
\hline $70-74$ & 714 & \multicolumn{2}{|c|}{$(40.2)$} & 612 & \multicolumn{2}{|c|}{$(44.4)$} & 102 & \multicolumn{2}{|c|}{$(25.5)$} & & & 1.00 \\
\hline $75-79$ & 667 & \multirow{2}{*}{\multicolumn{2}{|c|}{$\begin{array}{l}(37.5) \\
(22.3)\end{array}$}} & 508 & \multicolumn{2}{|c|}{$(36.9)$} & 159 & \multicolumn{2}{|c|}{ (39.8) } & $<0.001$ & 1.88 & $(1.43-2.47)^{* * *}$ \\
\hline$\geq 80$ & 397 & & & 258 & \multicolumn{2}{|c|}{ (18.7) } & 139 & \multicolumn{2}{|c|}{$(34.8)$} & & 3.23 & $(2.41-4.34)^{* * *}$ \\
\hline Female sex $(\%)$ & 961 & \multicolumn{2}{|c|}{$(54.0)$} & 769 & \multicolumn{2}{|c|}{$(55.8)$} & 192 & \multicolumn{2}{|c|}{$(48.0)$} & 0.006 & 0.73 & $(0.58-0.91) *$ \\
\hline Education (years) & 9.6 & \pm & 4.9 & 9.6 & \pm & 4.9 & 9.8 & \pm & 4.9 & 0.381 & 1.01 & $(0.99-1.03)$ \\
\hline Living alone & 376 & \multicolumn{2}{|c|}{$(21.1)$} & 296 & \multicolumn{2}{|c|}{$(21.5)$} & 80 & \multicolumn{2}{|c|}{$(20.0)$} & 0.523 & 0.91 & $(0.69-1.21)$ \\
\hline $\begin{array}{l}\text { Marital status (without } \\
\text { partner) }\end{array}$ & 562 & \multicolumn{2}{|c|}{$(31.6)$} & 445 & \multicolumn{2}{|c|}{$(32.3)$} & 117 & \multicolumn{2}{|c|}{$(29.3)$} & 0.249 & 0.87 & $(0.68-1.11)$ \\
\hline Socioeconomic status & 136 & \multicolumn{2}{|c|}{$(7.6)$} & 110 & \multicolumn{2}{|c|}{$(8.0)$} & 26 & \multicolumn{2}{|c|}{$(6.5)$} & 0.326 & 0.80 & $(0.51-1.25)$ \\
\hline \multicolumn{13}{|l|}{ Health-related factors } \\
\hline Current smoker & 89 & \multicolumn{2}{|c|}{$(5.0)$} & 57 & \multicolumn{2}{|c|}{$(4.1)$} & 32 & \multicolumn{2}{|c|}{$(8.0)$} & 0.002 & 2.02 & $(1.29-3.15)^{* *}$ \\
\hline $\begin{array}{l}\text { Alcohol consumption } \\
(\geq 2-3 \text { times/week) }\end{array}$ & 312 & & & 234 & & & 78 & & & 0.244 & 1.18 & $(0.89-1.57)$ \\
\hline Low physical activity & 154 & & & 101 & & & 53 & & & $<0.001$ & 1.93 & $(1.36-2.75) * * *$ \\
\hline $\begin{array}{l}\text { Poor nutritional status } \\
\text { (MNA-SF score of } \leq 11 \text { ) }\end{array}$ & 134 & & & 84 & & & 50 & & & $<0.001$ & 2.20 & $(1.52-3.18)^{* * *}$ \\
\hline Hypertension & 1047 & & & 806 & & & 241 & & & 0.529 & 1.08 & $(0.86-1.35)$ \\
\hline Diabetes & 406 & & & 295 & & & 111 & & & 0.008 & 1.41 & $(1.09-1.82) *$ \\
\hline Cardiovascular diseases & 223 & & & 176 & & & 47 & & & 0.587 & 0.91 & $(0.65-1.28)$ \\
\hline Osteoporosis & 295 & & & 215 & & & 80 & & & 0.037 & 1.35 & $(1.02-1.80) *$ \\
\hline Number of comorbidities & 1.8 & \pm & 1.3 & 1.8 & \pm & 1.3 & 1.9 & \pm & 1.3 & 0.147 & 1.07 & $(0.98-1.16)$ \\
\hline Number of medications & 3.5 & \pm & 2.8 & 3.4 & \pm & 2.8 & 3.9 & \pm & 2.8 & $<0.001$ & 1.07 & $(1.03-1.11)^{* * *}$ \\
\hline $\mathrm{BMI}\left(\mathrm{kg} / \mathrm{m}^{2}\right)$ & 24.5 & \pm & 2.9 & 25.0 & \pm & 2.9 & 23.0 & \pm & 2.7 & $<0.001$ & 0.77 & $(0.74-0.81)^{* * *}$ \\
\hline
\end{tabular}


Table 1. Cont.

\begin{tabular}{|c|c|c|c|c|c|c|c|c|c|c|c|c|}
\hline \multirow{2}{*}{$\begin{aligned} \text { Variables } \\
<18.5\end{aligned}$} & \multicolumn{3}{|c|}{ Overall $(n=1778)$} & \multicolumn{3}{|c|}{$\begin{array}{l}\text { Non-Sarcopenia Group } \\
(n=1378)\end{array}$} & \multicolumn{3}{|c|}{$\begin{array}{l}\text { Sarcopenia Group } \\
\qquad(n=400)\end{array}$} & \multirow{4}{*}{$\begin{array}{c}p \text {-Value }{ }^{\dagger} \\
<0.001\end{array}$} & \multirow{4}{*}{$\begin{array}{l}\text { OR } \\
\\
0.29 \\
0.09\end{array}$} & \multirow{2}{*}{$\begin{array}{l}(95 \% \text { CI }) \ddagger \\
1.00\end{array}$} \\
\hline & 34 & \multicolumn{2}{|c|}{$(1.9)$} & 14 & \multicolumn{2}{|c|}{$(1.0)$} & 20 & \multicolumn{2}{|c|}{$(5.0)$} & & & \\
\hline $18.5-24.9$ & 1021 & \multicolumn{2}{|c|}{$(57.4)$} & 724 & \multicolumn{2}{|c|}{$(52.5)$} & 297 & \multicolumn{2}{|c|}{ (74.3) } & & & $(1.14-0.58)^{* * *}$ \\
\hline$\geq 25.0$ & 723 & \multicolumn{2}{|c|}{$(40.7)$} & 640 & \multicolumn{2}{|c|}{$(46.4)$} & 83 & \multicolumn{2}{|c|}{$(20.8)$} & & & $(0.04-0.19) * * *$ \\
\hline \multicolumn{13}{|l|}{ Psychosocial factors } \\
\hline $\begin{array}{l}\text { Depressive symptoms } \\
\text { (SGDS-K score of } \geq 6 \text { ) }\end{array}$ & 378 & \multicolumn{2}{|c|}{$(21.3)$} & 265 & \multicolumn{2}{|c|}{$(19.2)$} & 113 & \multicolumn{2}{|c|}{$(28.2)$} & $<0.001$ & 1.65 & $(1.28-2.14)^{* * *}$ \\
\hline $\begin{array}{l}\text { Fair/poor self-perceived } \\
\text { health }\end{array}$ & 472 & \multicolumn{2}{|c|}{$(26.5)$} & 327 & \multicolumn{2}{|c|}{$(23.7)$} & 145 & \multicolumn{2}{|c|}{$(36.3)$} & $<0.001$ & 1.83 & $(1.44-2.32)^{* * *}$ \\
\hline $\begin{array}{l}\text { Cognitive function } \\
\text { (MMSE score of <24) }\end{array}$ & 288 & \multicolumn{2}{|c|}{$(16.2)$} & 201 & \multicolumn{2}{|c|}{$(14.6)$} & 87 & \multicolumn{2}{|c|}{$(21.8)$} & 0.001 & 1.63 & $(1.23-2.16)^{* * *}$ \\
\hline \multicolumn{13}{|l|}{ Social factors } \\
\hline $\begin{array}{l}\text { Participation in social } \\
\text { meetings (yes) }\end{array}$ & 1661 & \multicolumn{2}{|c|}{$(93.4)$} & 1296 & \multicolumn{2}{|c|}{$(94.0)$} & 365 & \multicolumn{2}{|c|}{ (91.3) } & 0.047 & 1.52 & $(1.00-2.29)^{*}$ \\
\hline Sarcopenia & & & & & & & & & & & & \\
\hline Handgrip strength (kg) & 26.5 & \pm & 7.4 & 27.2 & \pm & 7.6 & 24.2 & \pm & 6.4 & $<0.001$ & 0.94 & $(0.93-0.96) * * *$ \\
\hline Usual gait speed $(\mathrm{m} / \mathrm{s})$ & 1.1 & \pm & 0.2 & 1.2 & \pm & 0.3 & 1.0 & \pm & 0.2 & $<0.001$ & 0.08 & $(0.04-0.13) * * *$ \\
\hline $\begin{array}{l}\text { Five-times sit-to-stand } \\
\text { score }(\mathrm{s})\end{array}$ & 11.1 & \pm & 3.7 & 10.5 & \pm & 3.4 & 13.0 & \pm & 3.8 & $<0.001$ & 1.19 & $(1.15-1.23)^{* * *}$ \\
\hline SPPB score & 11.0 & \pm & 1.3 & 11.2 & \pm & 1.3 & 10.4 & \pm & 1.4 & $<0.001$ & 0.68 & $(0.62-0.73)^{* * *}$ \\
\hline $\begin{array}{l}\text { SMI-appendicular } \\
\left(\mathrm{kg} / \mathrm{m}^{2}\right)\end{array}$ & 6.4 & \pm & 1.0 & 6.6 & \pm & 1.0 & 5.7 & \pm & 0.8 & $<0.001$ & 0.30 & $(0.25-0.35)^{* * *}$ \\
\hline Neighborhood environment & & & & & & & & & & & & \\
\hline IPAQ-E total score (16-65) & 55.1 & \pm & 7.3 & 55.3 & \pm & 7.2 & 54.2 & \pm & 7.6 & 0.005 & 0.98 & $(0.96-0.98)^{* *}$ \\
\hline Residential density $(0-1)$ & 0.7 & \pm & 0.5 & 0.7 & \pm & 0.5 & 0.7 & \pm & 0.5 & 0.346 & 0.89 & $(0.70-1.13)$ \\
\hline $\begin{array}{l}\text { Access to destinations } \\
(5-20)\end{array}$ & 17.7 & \pm & 2.5 & 17.8 & \pm & 2.4 & 17.2 & \pm & 2.8 & $<0.001$ & 0.91 & $(0.87-0.95)^{* * *}$ \\
\hline $\begin{array}{l}\text { Neighborhood } \\
\text { infrastructure }(4-16)\end{array}$ & 13.5 & \pm & 2.7 & 13.5 & \pm & 2.7 & 13.5 & \pm & 2.6 & 0.925 & 1.00 & $(0.96-1.04)$ \\
\hline $\begin{array}{l}\text { Neighborhood safety } \\
(4-16)\end{array}$ & 13.3 & \pm & 2.5 & 13.4 & \pm & 2.5 & 13.1 & \pm & 2.6 & 0.035 & 0.95 & $(0.91-1.00) *$ \\
\hline Social environment $(1-4)$ & 3.5 & \pm & 0.8 & 3.5 & \pm & 0.8 & 3.4 & \pm & 0.8 & 0.246 & 0.93 & $(0.81-1.05)$ \\
\hline Aesthetic qualities $(1-4)$ & 3.1 & \pm & 1.1 & 3.1 & \pm & 1.1 & 3.0 & \pm & 1.1 & 0.118 & 0.92 & $(0.84-1.02)$ \\
\hline Street connectivity $(1-4)$ & 3.3 & \pm & 0.9 & 3.3 & \pm & 0.9 & 3.3 & \pm & 0.9 & 0.838 & 0.99 & $(0.87-1.12)$ \\
\hline
\end{tabular}

Values are presented as either means \pm standard deviations or $n(\%)$. IPAQ-E $=$ International Physical Activity Questionnaire Environment Module; BMI = body mass index; IADL = Instrumental Activities Daily Living; SGDS-K = Korean Version of Short Form Geriatric Depression Scale; MMSE = Mini-Mental State Examination; MNA-SF = Mini Nutritional Assessment Short Form; SPPB = Short Physical Performance Battery; $\mathrm{SMI}=$ Skeletal muscle mass index; $\mathrm{CI}=$ confidence interval; $\mathrm{OR}=$ odds ratio. ${ }^{\dagger} p$-values are based on the chi-square test or independent t-test. ${ }^{*} p<0.05,{ }^{* *} p<0.01,{ }^{* * *} p<0.005$. ${ }^{\ddagger}$ Association between characteristics of participants by non-sarcopenia and sarcopenia groups by univariate logistic regression analysis.

\subsection{Neighborhood Environmental Factors Associated with Sarcopenia}

The non-sarcopenia group had a significantly higher IPAQ-E score $(p=0.005)$, access to destinations score $(p<0.001)$, and neighborhood safety score $(p=0.035)$ (Table 1$)$. Table 2 shows the association between neighborhood environmental factors and sarcopenia. Logistic regression analyses showed that no access to public transport $(\mathrm{OR}=2.04$; $95 \% \mathrm{CI}=1.19-3.48)$, poor access to recreational facilities $(\mathrm{OR}=1.39 ; 95 \% \mathrm{CI}=1.01-1.90)$, absence of destination $(\mathrm{OR}=1.53 ; 95 \% \mathrm{CI}=1.06-2.20)$, many hill hazards $(\mathrm{OR}=1.36$; $95 \% \mathrm{CI}=1.03-1.78)$, and lack of traffic safety $(\mathrm{OR}=1.35,95 \% \mathrm{CI}=1.02-1.78)$ were significantly associated with sarcopenia after adjusting for potentially confounding variables (Model 4).

We further identified the AR and population PAR of five perceived neighborhood environmental factors with significance in the logistic regression analysis for sarcopenia, as presented in Appendix A, Table A2. Among the five environmental factors, no access to public transportation was the most significant contributing factor for sarcopenia (Appendix A, Table A2). 
Table 2. Adjusted odds ratios of neighborhood environmental factors for sarcopenia $(n=1778)$.

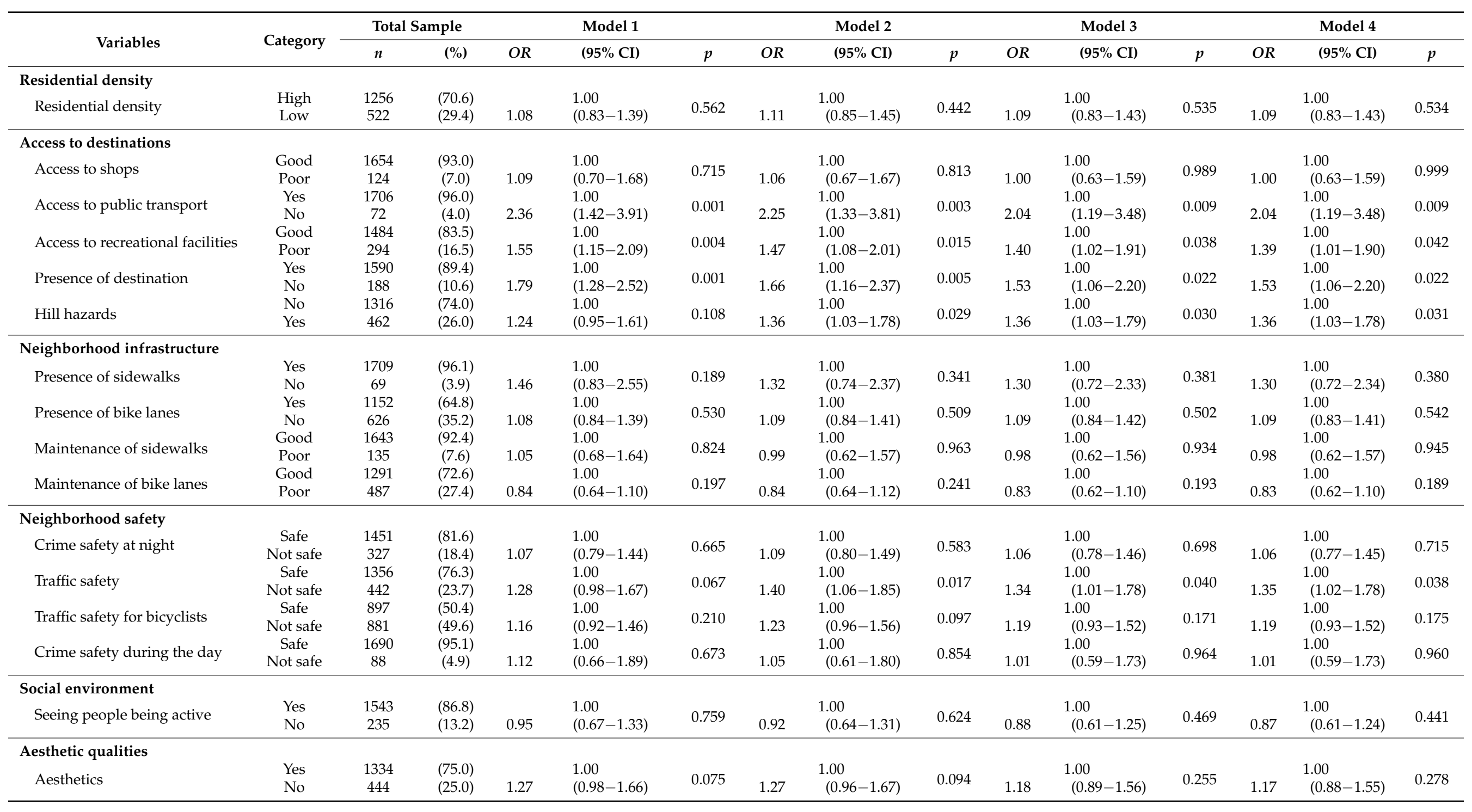


Table 2. Cont.

\begin{tabular}{|c|c|c|c|c|c|c|c|c|c|c|c|c|c|c|c|}
\hline \multirow{2}{*}{ Variables } & \multirow{2}{*}{ Category } & \multicolumn{2}{|c|}{ Total Sample } & \multicolumn{3}{|c|}{ Model 1} & \multicolumn{3}{|c|}{ Model 2} & \multicolumn{3}{|c|}{ Model 3} & \multicolumn{3}{|c|}{ Model 4} \\
\hline & & $n$ & $(\%)$ & OR & $(95 \% \mathrm{CI})$ & $p$ & OR & $(95 \% \mathrm{CI})$ & $p$ & OR & $(95 \% \mathrm{CI})$ & $p$ & OR & $(95 \% \mathrm{CI})$ & $p$ \\
\hline \multicolumn{16}{|l|}{ Street connectivity } \\
\hline Connectivity of streets & $\begin{array}{l}\text { Yes } \\
\text { No }\end{array}$ & $\begin{array}{l}1499 \\
279\end{array}$ & $\begin{array}{l}(84.3) \\
(15.7)\end{array}$ & 0.98 & $\begin{array}{l}1.00 \\
(0.71-1.35)\end{array}$ & 0.902 & 0.94 & $\begin{array}{l}1.00 \\
(0.67-1.31)\end{array}$ & 0.707 & 0.94 & $\begin{array}{l}1.00 \\
(0.67-1.32)\end{array}$ & 0.722 & 0.93 & $\begin{array}{l}1.00 \\
(0.66-1.31)\end{array}$ & 0.685 \\
\hline
\end{tabular}

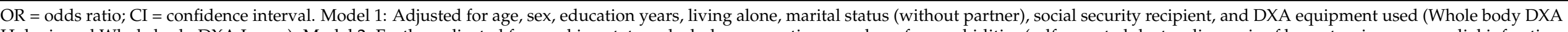

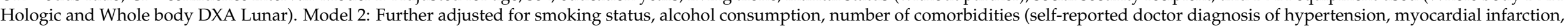

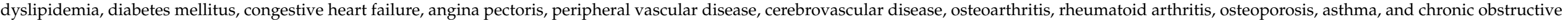

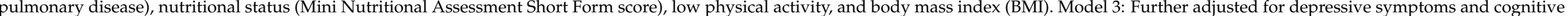

function (Mini-Mental State Examination total score). Model 4: Further adjusted for participation in social meetings (social capital) 


\subsection{Neighborhood Environmental Total Score Associated with Sarcopenia}

Figure 2 shows the adjusted odds ratios of the IPAQ-E total score quintiles for sarcopenia. After adjusted for potentially confounding variables (Model 4), compared to the IPAQ-E total score in the fifth quintile, the ORs for sarcopenia in the first, second, third, and fourth quintiles were $2.13(95 \% \mathrm{CI}=1.40-3.24), 1.72(95 \% \mathrm{CI}=1.12-2.64), 1.75$ $(95 \% \mathrm{CI}=1.15-2.66)$, and $1.62(95 \% \mathrm{CI}=1.06-2.47)$, respectively.

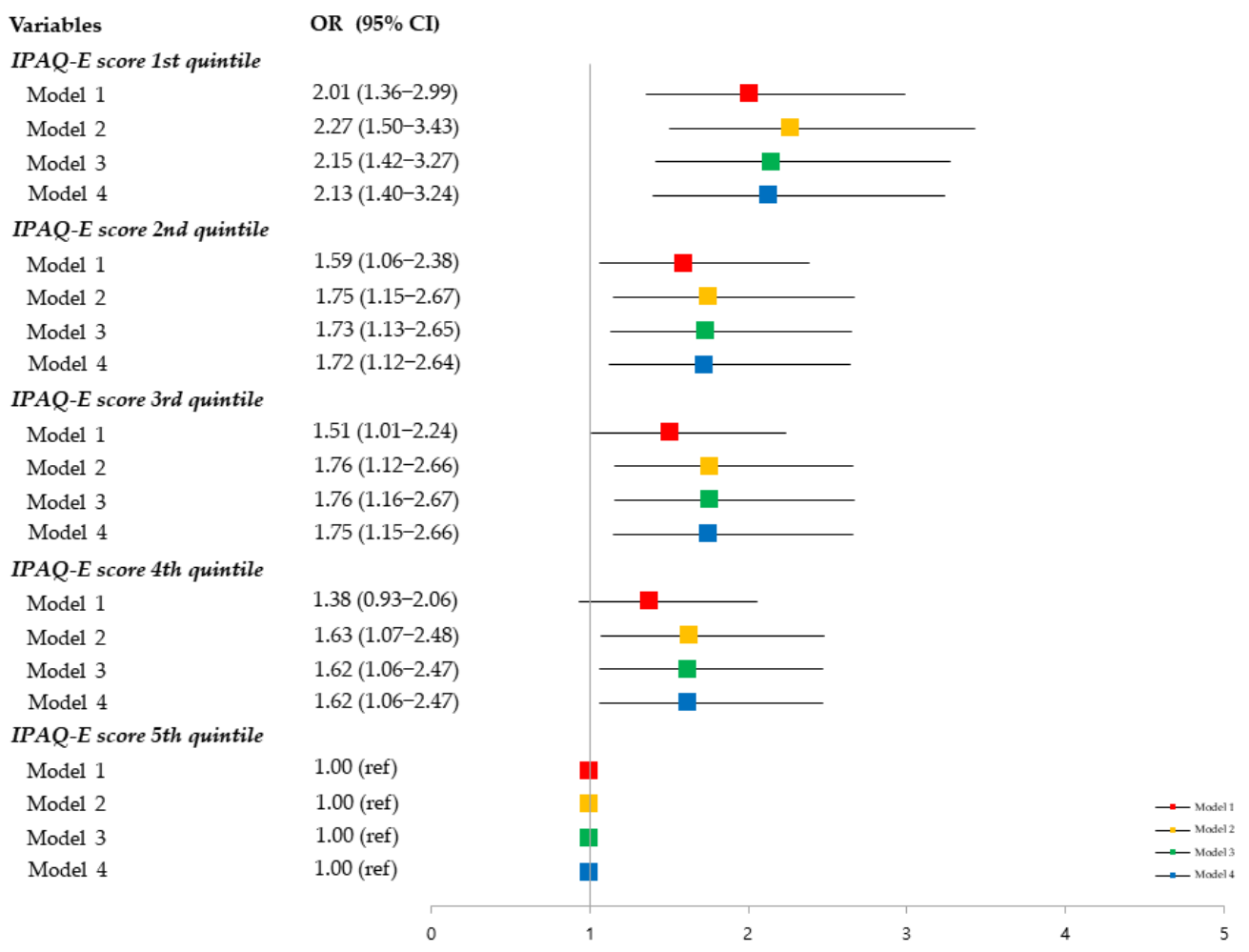

Figure 2. Adjusted odds ratios (ORs) and 95\% confidence intervals (CIs) of the IPAQ-E score quintiles for sarcopenia. Model 1: Adjusted for sociodemographic variables (age, sex, education, living alone, marital status, and social security recipient) and DXA equipment used. Model 2: Further adjusted for health-related lifestyle variables (smoking status, alcohol consumption, number of comorbidities, nutritional status, low physical activity, and body mass index). Model 3: Further adjust for psychosocial variables (depressive symptoms and cognitive function). Model 4: Further adjusted for social variables (participation in social meetings).

\section{Discussion}

To the best of our knowledge, the current study was the first to examine the association between perceived neighborhood environment and sarcopenia in urban-dwelling older adults, which found that five environmental factors (no access to public transport, poor recreational facilities, absence of destination, many hill hazards, and lack of traffic safety) were significantly associated with sarcopenia.

We confirmed the relationship between physical frailty and perceived neighborhood environment in our previous study [12]. Sarcopenia is a core component of physical frailty [36] and is a common risk factor [5]. Therefore, perceived neighborhood environment that reduces the risk of physical frailty is likely to be related to sarcopenia. Our study found that after adjusting for potential confounding variables, a low IPAQ-E total score was associated with an increased prevalence of sarcopenia. Okuyama et al. confirmed whether neighborhood environmental factors, such as hilliness, bus stop density, intersection density, residential density, and distance to community centers, were associated with muscle mass and grip strength in older adults after a 3-year follow-up period [18]. In the Okuyama's study, the measurement of the neighborhood environment was calculated within a 1000-m network buffer from each participant's residence location based on an 
actual street network using geographic information systems [18]. However, our study differed from previous studies in that it was evaluated with comprehensive and perceived neighborhood environment tools including aesthetic environment, safety, infrastructure (sidewalks, bike lanes) and social environment. In addition, a systematic review identified a positive association between the neighborhood-built environment and physical function, although physical function was measured using basic ADL [37]. These studies were evaluated sarcopenia components or self-reported physical ability, and not sarcopenia itself. Therefore, our study confirmed that the association differs from previous studies of sarcopenia itself, including the perceived neighborhood environment total score and the individual components. Our results showed that perceived neighborhood environmentespecially factors of no access to public transport, poor recreational facilities, absence of destination, many hill hazards, and lack of traffic safety—were related to sarcopenia, even after controlling for potential covariates.

Our study found that poor access to public transport was the most significant neighborhood environmental factor contributing to sarcopenia (46.0\% [45.2-46.8]). Access to public transport means that it is less than a 10-15-min walk to a transit station (bus stop, train subway station) from a participant's home. In a previous study, the use of public transportation increased the amount of walking activity, which decreased the risk of obesity and reduced sedentary time [38]. Thus, the use of public transportation can promote an active lifestyle for older adults. Previous studies have shown that public transportation is essential for older people with poor health (for example, functional impairment) because it creates an environment that is easy to navigate on their own, without depending on others [39]. In addition, our results indicated that physical environmental factors, including hill hazards, traffic safety, and recreational facilities, might be associated with sarcopenia. Negative perceptions of these environments may lead to lower physical activity due to restrictions in using active life spaces [39,40]. Several studies have shown that physical inactivity may be associated with an increased risk of chronic diseases, modifications in body composition (increased fat and decreased muscle mass), and premature death [41-43]. A systematic review also showed that inactive older persons had an increased risk of sarcopenia [44]. Therefore, the poorer the perception of one's physical environment, the higher the risk of sarcopenia due to lower physical activity levels.

Our study also showed that the absence of a destination was significantly associated with sarcopenia. The absence of a destination referred to the lack of public facilities, such as banks and post offices, that provide opportunities for social activities. Previous studies have shown that a lack of social resources can induce physical and social disabilities due to limited social integration and cohesion [45]. Therefore, the presence of a destination may allow older people to participate in social activities, which in turn may contribute to a healthy life. Specifically, one study showed that social support positively affected muscle mass, muscle strength, and physical function, which are components of sarcopenia [46]. In addition, the presence of a destination includes access to medical services. Thus, people who perceive insufficient access to medical services may experience difficulties in healthcare access [47]. For example, due to the lack of information on health, preventive care as well as opportunities for health maintenance and early treatment can be neglected [48,49]. Therefore, an environment that has no social attributes, such as absence to destinations, can affect sarcopenia in two ways: (i) lowering social interactions and (ii) interrupting one's ability to control their health.

This study had several limitations. First, our study participants were older adults that were recruited from an ambulatory community and were relatively healthy. Thus, our findings may not be applicable to other settings and populations. Second, our information on the perceived neighborhood environment was obtained by self-reported questionnaires using the IPAQ-E. We measured the perceived environment factors which might be independent of the objective environment characteristics. The objective measures are less biased and less fluctuating aspects of the environment, whereas perceived measures of the environment are influenced by social and cognitive factors [50]. Nevertheless, both objective and 
perceived neighborhood environmental attributes have been related to physical activity and behavior [51]. In our study, we found that poor perceived neighborhood environments were associated with sarcopenia, even after controlling for psychosocial and social factors as confounding variables. Furthermore, the IPAQ-E questionnaire has been suggested as reliable assessment tool [24], which has been used in several countries [21-23]. Moreover, perceived neighborhood environment may be shown to predict health and health behavior more than the objectively measured environment among older adults, making it convenient to evaluate various neighborhood environmental variables [50]. Future research is needed to investigate the relationship between direct and indirect neighborhood environment to sarcopenia through objective and perceived evaluation of the neighborhood environment.

Third, the cross-sectional study design did not allow us to establish causal relationships between the perceived neighboring environment and two variables of sarcopenia. In the future, a longitudinal study design is needed to substantiate this relationship. Nevertheless, this study had major strengths, such as including a large nationally representative sample of community-dwelling older Korean adults, using a comprehensive measure of the perceived neighborhood environment (analysis of environmental factors considering the characteristics of the neighborhood environment), and including various covariates in the analysis.

\section{Conclusions}

Our study findings indicate that poor perceived neighborhood environments were associated with sarcopenia among urban-dwelling older adults, even after controlling for physical health conditions as confounding variables. Furthermore, perceived neighborhood environment factors, including physical activity and social participation, were related to sarcopenia. Our findings have implications in the prevention and management of sarcopenia among older adults for city planners and public health workers as they add to the literature on the association between the neighborhood-built environment and sarcopenia.

Author Contributions: Conceptualization, M.K. and C.W.; methodology, Y.S., M.K. and C.W.; formal analysis, Y.S.; investigation and data curation, Y.S., M.K. and C.W.; writing-original draft preparation, Y.S. and H.S.; writing-review and editing, M.K. and C.W.; supervision, M.K. and C.W.; project administration, Y.S.; funding acquisition, C.W. All authors have read and agreed to the published version of the manuscript.

Funding: This research was supported by a grant from the Korea Health Technology R\&D Project through the Korea Health Industry Development Institute (KHIDI), funded by the Ministry of Health and Welfare, Republic of Korea (grant number: HI15C3153).

Institutional Review Board Statement: The study was conducted according to the guidelines of the Declaration of Helsinki and approved by the Institutional Review Board of Kyung Hee University (IRB number: 2015-12-103).

Informed Consent Statement: Informed consent was obtained from all the participants involved in the study.

Data Availability Statement: Data can be provided on request from corresponding authors.

Acknowledgments: We would like to thank the study participants and staff of the Korean Frailty and Aging Cohort Study for their cooperation in this study.

Conflicts of Interest: The authors declare no conflict of interest. 


\section{Appendix A}

Table A1. The 17 items of the International Physical Activity Questionnaire Environmental Module and scoring methods.

\begin{tabular}{|c|c|c|c|c|c|}
\hline \multirow[b]{2}{*}{ Residential density (1 item) } & \multirow[t]{2}{*}{ Contents } & \multicolumn{4}{|c|}{ Response Categories/Scoring Method } \\
\hline & & $\begin{array}{l}\text { Single- } \\
\text { family } \\
\text { housing }\end{array}$ & $\begin{array}{l}\text { Apartments } \\
\text { with 2-3 } \\
\text { stories }\end{array}$ & $\begin{array}{l}\text { Mix of } \\
\text { single-family } \\
\text { housing and } \\
\text { apartments with } \\
2-3 \text { stories }\end{array}$ & $\begin{array}{c}\text { Condos with } \\
4-12 \text { stories, and } \\
\text { condos with }>13 \\
\text { stories }\end{array}$ \\
\hline Type of housing & $\begin{array}{l}\text { What is the main type of housing } \\
\text { in your neighborhood? }\end{array}$ & 0 & 1 & 1 & 1 \\
\hline $\begin{array}{l}\text { Access to destinations } \\
\text { (5 items) }\end{array}$ & & $\begin{array}{l}\text { Strongly } \\
\text { disagree }\end{array}$ & $\begin{array}{l}\text { Somewhat } \\
\text { disagree }\end{array}$ & Somewhat agree & Strongly agree \\
\hline Access to shops & $\begin{array}{l}\text { Many shops are within walking } \\
\text { distance of my home }\end{array}$ & 1 & 2 & 3 & 4 \\
\hline Access to public transport & $\begin{array}{l}\text { It is less than a } 10-15-\text { min walk } \\
\text { to a transit station from my home }\end{array}$ & 1 & 2 & 3 & 4 \\
\hline Access to recreational facilities & $\begin{array}{l}\text { My neighborhood has several free } \\
\text { or low-cost recreational facilities } \\
\text { There are many destinations }\end{array}$ & 1 & 2 & 3 & 4 \\
\hline Presence of destinations & $\begin{array}{l}\text { around the house, such as banks, } \\
\text { post offices, medical institutions, } \\
\text { and public facilities }\end{array}$ & 1 & 2 & 3 & 4 \\
\hline Hill hazards * & $\begin{array}{l}\text { It is not easy to walk to your } \\
\text { destination because of the many } \\
\text { hills or slopes around your house }\end{array}$ & 4 & 3 & 2 & 1 \\
\hline $\begin{array}{l}\text { Neighborhood infrastructure } \\
\text { (4 items) }\end{array}$ & & $\begin{array}{l}\text { Strongly } \\
\text { disagree }\end{array}$ & $\begin{array}{l}\text { Somewhat } \\
\text { disagree }\end{array}$ & Somewhat agree & Strongly agree \\
\hline Presence of sidewalks & $\begin{array}{l}\text { There are sidewalks on most of } \\
\text { the streets in my neighborhood }\end{array}$ & 1 & -5 & 3 & 4 \\
\hline Presence of bike lanes & $\begin{array}{l}\text { There are facilities to cycle in or } \\
\text { near my neighborhood } \\
\text { The sidewalks in my }\end{array}$ & 1 & 2 & 3 & 4 \\
\hline Maintenance of sidewalks & $\begin{array}{l}\text { neighborhood are } \\
\text { well-maintained and not } \\
\text { obstructed }\end{array}$ & 1 & 2 & 3 & 4 \\
\hline Maintenance of bike lanes & $\begin{array}{l}\text { Places for cycling in and around } \\
\text { my neighborhood are } \\
\text { well-maintained and not } \\
\text { obstructed }\end{array}$ & 1 & 2 & 3 & 4 \\
\hline $\begin{array}{l}\text { Neighborhood safety } \\
\text { (4 items) }\end{array}$ & & $\begin{array}{l}\text { Strongly } \\
\text { disagree }\end{array}$ & $\begin{array}{l}\text { Somewhat } \\
\text { disagree }\end{array}$ & Somewhat agree & Strongly agree \\
\hline Crime safety at night * & $\begin{array}{l}\text { The crime rate in my } \\
\text { neighborhood makes it unsafe to } \\
\text { go on walks at night }\end{array}$ & 4 & 3 & 2 & 1 \\
\hline Traffic safety * & $\begin{array}{l}\text { There is so much traffic on the } \\
\text { streets that walking is difficult or } \\
\text { unpleasant }\end{array}$ & 4 & 3 & 2 & 1 \\
\hline Traffic safety for bicyclists * & $\begin{array}{l}\text { There is so much traffic on the } \\
\text { streets that it makes it difficult or } \\
\text { unpleasant to ride a bicycle in my } \\
\text { neighborhood }\end{array}$ & 4 & 3 & 2 & 1 \\
\hline Crime safety during the day ${ }^{*}$ & $\begin{array}{l}\text { The crime rate in my } \\
\text { neighborhood makes it unsafe to } \\
\text { go on walks during the day }\end{array}$ & 4 & 3 & 2 & 1 \\
\hline Social environment ( 1 item) & & $\begin{array}{l}\text { Strongly } \\
\text { disagree }\end{array}$ & $\begin{array}{l}\text { Somewhat } \\
\text { disagree }\end{array}$ & Somewhat agree & Strongly agree \\
\hline Seeing people being active & $\begin{array}{l}\text { I see many people being } \\
\text { physically active in my } \\
\text { neighborhood }\end{array}$ & 1 & 2 & 3 & 4 \\
\hline Aesthetic qualities (1 item) & & $\begin{array}{l}\text { Strongly } \\
\text { disagree }\end{array}$ & $\begin{array}{l}\text { Somewhat } \\
\text { disagree }\end{array}$ & Somewhat agree & Strongly agree \\
\hline Aesthetics & $\begin{array}{l}\text { There are many interesting things } \\
\text { to look at while walking in my } \\
\text { neighborhood }\end{array}$ & 1 & 2 & 3 & 4 \\
\hline
\end{tabular}


Table A1. Cont.

\begin{tabular}{|c|c|c|c|c|c|}
\hline Scale Composition & Contents & & Response Ca & ories/Scoring Met & \\
\hline Street connectivity (1 item) & & $\begin{array}{l}\text { Strongly } \\
\text { disagree }\end{array}$ & $\begin{array}{c}\text { Somewhat } \\
\text { disagree }\end{array}$ & Somewhat agree & Strongly agree \\
\hline Connectivity of streets & $\begin{array}{l}\text { There are many four-way } \\
\text { intersections in my neighborhood }\end{array}$ & 1 & 2 & 3 & 4 \\
\hline
\end{tabular}

Total possible score $=65$

Scores were dichotomized as follows: $1-2$ points $=0$ point; $3-4$ points $=1$ point. * Reverse scoring.

Table A2. Attributable risk (AR) and population attributable risk (PAR) of neighborhood environmental five factors for sarcopenia $(n=1778)$.

\begin{tabular}{|c|c|c|c|c|c|}
\hline Variables & $\begin{array}{l}\text { Sarcopenia } \\
\quad(n=400)\end{array}$ & $\begin{array}{l}\text { Non-Sarcopenia } \\
\quad(n=1378)\end{array}$ & $\begin{array}{l}\text { RR for Sarcopenia } \\
\qquad(95 \% \text { CI })\end{array}$ & $\begin{array}{c}\text { Attributable Risk } \\
\text { (AR\%) }\end{array}$ & $\begin{array}{l}\text { Population AR } \\
\text { (PAR\%) }\end{array}$ \\
\hline \multicolumn{6}{|c|}{ Access to public transport } \\
\hline Yes (ref) & 371 & 1335 & 1.00 & & \\
\hline No & 29 & 43 & $1.85(1.83-1.87)$ & $46.0 \%(45.2-46.8)$ & $3.3 \%$ \\
\hline \multicolumn{6}{|l|}{$\begin{array}{l}\text { Access to recreational } \\
\text { facilities }\end{array}$} \\
\hline Good (ref) & 317 & 1167 & 1.00 & & \\
\hline Poor & 83 & 211 & $1.32(1.31-1.33)$ & $24.3 \%(23.7-24.9)$ & $5.0 \%$ \\
\hline \multicolumn{6}{|c|}{ Presence of destination } \\
\hline Yes (ref) & 339 & 1251 & 1.00 & & \\
\hline No & 61 & 127 & $1.52(1.51-1.53)$ & $34.3 \%(33.7-34.9)$ & $5.2 \%$ \\
\hline \multicolumn{6}{|l|}{ Hill hazards } \\
\hline No (ref) & 279 & 1037 & 1.00 & & \\
\hline Yes & 121 & 341 & $1.24(1.23-1.24)$ & $19.1 \%(18.5-19.6)$ & $5.8 \%$ \\
\hline \multicolumn{6}{|l|}{ Traffic safety } \\
\hline Safe (ref) & 291 & 1065 & 1.00 & & \\
\hline Not safe & 109 & 313 & $1.20(1.20-1.21)$ & $16.9 \%(16.4-17.5)$ & $4.6 \%$ \\
\hline
\end{tabular}

$\mathrm{RR}=$ relative risk; $\mathrm{AR}=$ attributable risk; $\mathrm{PAR}=$ population attributable risk.

\section{References}

1. Cruz-Jentoft, A.J.; Sayer, A.A. Sarcopenia. Lancet 2019, 393, 2636-2646. [CrossRef]

2. Mijnarends, D.; Luiking, Y.; Halfens, R.; Evers, S.; Lenaerts, E.; Verlaan, S.; Wallace, M.; Schols, J.M.; Meijers, J. Muscle, health and costs: A glance at their relationship. J. Nutr. Health Aging 2018, 22, 766-773. [CrossRef] [PubMed]

3. Bruyère, O.; Beaudart, C.; Ethgen, O.; Reginster, J.-Y.; Locquet, M. The health economics burden of sarcopenia: A systematic review. Maturitas 2019, 119, 61-69. [CrossRef] [PubMed]

4. Shafiee, G.; Keshtkar, A.; Soltani, A.; Ahadi, Z.; Larijani, B.; Heshmat, R. Prevalence of sarcopenia in the world: A systematic review and meta-analysis of general population studies. J. Diabetes Metab. Disord. 2017, 16, 21. [CrossRef] [PubMed]

5. Patel, H.P.; Clift, E.; Lewis, L.; Cooper, C. Epidemiology of sarcopenia and frailty. In Frailty and Sarcopenia-Onset, Development and Clinical Challenges; Dionyssiotis, Y., Ed.; Intech Open: Vienna, Austria, 2017; ISBN 978-9-53513-483-1.

6. Kawachi, I. Applications of behavioral economics to improve health. In Social Epidemiology; Oxford University Press: Oxford, UK, 2014.

7. World Health Organization. Global Age-Friendly Cities: A Guide; World Health Organization: Geneva, Switzerland, 2007; ISBN 978-9-24154-730-7.

8. World Health Organization. World Report on Ageing and Health; World Health Organization: Geneva, Switzerland, 2015; ISBN 978-9-24156-504-2.

9. Nicklett, E.J.; Lohman, M.C.; Smith, M.L. Neighborhood Environment and Falls among Community-Dwelling Older Adults. Int J. Environ. Res. Public Health 2017, 14, 175. [CrossRef]

10. Gobbens, R.J.J. Cross-sectional and Longitudinal Associations of Environmental Factors with Frailty and Disability in Older People. Arch. Gerontol. Geriatr. 2019, 85, 103901. [CrossRef] [PubMed]

11. Fritz, H.; Cutchin, M.P.; Gharib, J.; Haryadi, N.; Patel, M.; Patel, N. Neighborhood characteristics and frailty: A scoping review. Gerontologist 2020, 60, e270-e285. [CrossRef] [PubMed]

12. Seo, Y.; Kim, M.; Shim, H.; Won, C.W. Differences in the Association of Neighborhood Environment With Physical Frailty Between Urban and Rural Older Adults: The Korean Frailty and Aging Cohort Study (KFACS). J. Am. Med. Dir. Assoc. 2020, 22, 590-597.e1. [CrossRef] 
13. Yen, I.H.; Michael, Y.L.; Perdue, L. Neighborhood environment in studies of health of older adults: A systematic review. Am. J. Prev. Med. 2009, 37, 455-463. [CrossRef]

14. Barnett, A.; Zhang, C.J.P.; Johnston, J.M.; Cerin, E. Relationships between the neighborhood environment and depression in older adults: A systematic review and meta-analysis. Int. Psychogeriatr. 2018, 30, 1153-1176. [CrossRef]

15. Adams, M.A.; Sallis, J.F.; Conway, T.L.; Frank, L.D.; Saelens, B.E.; Kerr, J.; Cain, K.L.; King, A.C. Neighborhood environment profiles for physical activity among older adults. Am. J. Health Behav. 2012, 36, 757-769. [CrossRef]

16. Liao, Y.; Lai, T.-F.; Chang, C.-S.; Huang, W.-C.; Park, J.-H. A Nonlinear Association Between Neighborhood Walkability and Risks of Sarcopenia in Older Adults. J. Nutr. Health Aging 2020, 25, 618-623. [CrossRef]

17. Popkin, B.M.; Duffey, K.; Gordon-Larsen, P. Environmental influences on food choice, physical activity and energy balance. Physiol. Behav. 2005, 86, 603-613. [CrossRef]

18. Okuyama, K.; Abe, T.; Yano, S.; Sundquist, K.; Nabika, T. Neighborhood environment and muscle mass and function among rural older adults: A 3-year longitudinal study. Int. J. Health Geogr. 2020, 19, 1-12. [CrossRef]

19. Won, C.W.; Lee, S.; Kim, J.; Chon, D.; Kim, S.; Kim, C.O.; Kim, M.K.; Cho, B.; Choi, K.M.; Roh, E.; et al. Korean frailty and aging cohort study (KFACS): Cohort profile. BMJ Open 2020, 10, e035573. [CrossRef] [PubMed]

20. Alexander, A.; Bergman, P.; Hagströmer, M.; Sjöström, M. IPAQ environmental module; reliability testing. J. Public Health 2006, 14, 76. [CrossRef]

21. Liao, Y.; Harada, K.; Shibata, A.; Ishii, K.; Oka, K.; Nakamura, Y.; Inoue, S.; Shimomitsu, T. Perceived environmental factors associated with physical activity among normal-weight and overweight Japanese men. Int J. Environ. Res. Public Health 2011, 8, 931-943. [CrossRef] [PubMed]

22. Liao, Y.; Wang, I.; Hsu, H.-H.; Chang, S.-H. Perceived environmental and personal factors associated with walking and cycling for transportation in Taiwanese adults. Int. J. Environ. Res. Public Health 2015, 12, 2105-2119. [CrossRef]

23. Bergman, P.; Grjibovski, A.M.; Hagströmer, M.; Sallis, J.F.; Sjöström, M. The association between health enhancing physical activity and neighbourhood environment among Swedish adults-A population-based cross-sectional study. Int. J. Behav. Nutr. Phys. Act. 2009, 6, 8. [CrossRef]

24. Inoue, S.; Murase, N.; Shimomitsu, T.; Ohya, Y.; Odagiri, Y.; Takamiya, T.; Ishii, K.; Katsumura, T.; Sallis, J.F. Association of physical activity and neighborhood environment among Japanese adults. Prev. Med. 2009, 48, 321-325. [CrossRef]

25. Kim, M.-J.; Seo, S.-H.; Seo, A.-R.; Kim, B.-K.; Lee, G.-Y.; Choi, Y.-S.; Kim, J.-H.; Kim, J.-R.; Kang, Y.-S.; Jeong, B.-G. The Association of Perceived Neighborhood Walkability and Environmental Pollution With Frailty Among Community-dwelling Older Adults in Korean Rural Areas: A Cross-sectional Study. J. Prev. Med. Public Health 2019, 52, 405. [CrossRef]

26. Chen, L.-K.; Woo, J.; Assantachai, P.; Auyeung, T.-W.; Chou, M.-Y.; Iijima, K.; Jang, H.C.; Kang, L.; Kim, M.; Kim, S. Asian Working Group for Sarcopenia: 2019 consensus update on sarcopenia diagnosis and treatment. J. Am. Med. Dir. Assoc. 2020, 21, 300-307.e2. [CrossRef]

27. Cawthon, P.M.; Peters, K.W.; Shardell, M.D.; McLean, R.R.; Dam, T.-T.L.; Kenny, A.M.; Fragala, M.S.; Harris, T.B.; Kiel, D.P.; Guralnik, J.M. Cutpoints for low appendicular lean mass that identify older adults with clinically significant weakness. J. Gerontol. A Biol. Sci. Med. Sci. 2014, 69, 567-575. [CrossRef] [PubMed]

28. Kim, M.; Won, C.W.; Kim, M. Muscular grip strength normative values for a Korean population from the Korea National Health and Nutrition Examination Survey, 2014-2015. PLoS ONE 2018, 13, e0201275. [CrossRef]

29. Guralnik, J.M.; Simonsick, E.M.; Ferrucci, L.; Glynn, R.J.; Berkman, L.F.; Blazer, D.G.; Scherr, P.A.; Wallace, R.B. A short physical performance battery assessing lower extremity function: Association with self-reported disability and prediction of mortality and nursing home admission. J. Geriatr. 1994, 49, M85-M94. [CrossRef]

30. Guralnik, J.M.; Ferrucci, L.; Pieper, C.F.; Leveille, S.G.; Markides, K.S.; Ostir, G.V.; Studenski, S.; Berkman, L.F.; Wallace, R.B Lower extremity function and subsequent disability: Consistency across studies, predictive models, and value of gait speed alone compared with the short physical performance battery. J. Gerontol. A Biol. Sci. Med. Sci. 2000, 55, M221-M231. [CrossRef] [PubMed]

31. Won, C.W.; Yang, K.Y.; Rho, Y.G.; Kim, S.Y.; Lee, E.J.; Yoon, J.L.; Cho, K.H.; Shin, H.C.; Cho, B.R.; Oh, J.R. The development of Korean activities of daily living (K-ADL) and Korean instrumental activities of daily living (K-IADL) scale. J. Korea Gerontol. Soc. 2002, 6, 107-120.

32. Rubenstein, L.Z.; Harker, J.O.; Salvà, A.; Guigoz, Y.; Vellas, B. Screening for undernutrition in geriatric practice: Developing the short-form mini-nutritional assessment (MNA-SF). J. Gerontol. A Biol. Sci. Med. Sci. 2001, 56, M366-M372. [CrossRef] [PubMed]

33. Jo, M.-W.; Yun, S.-C.; Lee, S.-I. Estimating quality weights for EQ-5D health states with the time trade-off method in South Korea. Value Health 2008, 11, 1186-1189. [CrossRef]

34. Lee, S.C.; Kim, W.H.; Chang, S.M.; Kim, B.S.; Lee, D.W.; Bae, J.N.; Cho, M.J. The Use of the Korean Version of Short Form Geriatric Depression Scale (SGDS-K) in the Community Dwelling Elderly in Korea. J. Korean Geriatr. Psychiatry 2013, $17,37-43$.

35. Lee, D.Y.; Lee, K.U.; Lee, J.H.; Kim, K.W.; Jhoo, J.H.; Kim, S.Y.; Yoon, J.C.; Woo, S.I.; Ha, J.; Woo, J.I. A normative study of the CERAD neuropsychological assessment battery in the Korean elderly. J. Int. Neuropsychol. Soc. 2004, 10, 72. [CrossRef]

36. Nascimento, C.; Ingles, M.; Salvador-Pascual, A.; Cominetti, M.; Gomez-Cabrera, M.; Viña, J. Sarcopenia, frailty and their prevention by exercise. Free Radic. Biol. Med. 2019, 132, 42-49. [CrossRef]

37. Rachele, J.N.; Sugiyama, T.; Davies, S.; Loh, V.H.; Turrell, G.; Carver, A.; Cerin, E. Neighbourhood built environment and physical function among mid-to-older aged adults: A systematic review. Health Place 2019, 58, 102137. [CrossRef] 
38. Lindström, M. Means of transportation to work and overweight and obesity: A population-based study in southern Sweden. Prev. Med. 2008, 46, 22-28. [CrossRef] [PubMed]

39. Beard, J.R.; Blaney, S.; Cerda, M.; Frye, V.; Lovasi, G.S.; Ompad, D.; Rundle, A.; Vlahov, D. Neighborhood characteristics and disability in older adults. J. Gerontol. B Psychol. Sci. Soc. Sci. 2009, 64, 252-257. [CrossRef] [PubMed]

40. Martins, B.A.; Visvanathan, R.; Barrie, H.R.; Huang, C.H.; Matsushita, E.; Okada, K.; Satake, S.; Edwards, S.; Uno, C.; Kuzuya, M. Built Environment and Frailty: Neighborhood Perceptions and Associations With Frailty, Experience From the Nagoya Longitudinal Study. J. Appl. Gerontol. 2020, 0733464820912663. [CrossRef]

41. Anderson, E.; Durstine, J.L. Physical activity, exercise, and chronic diseases: A brief review. SMHS 2019, 1, 3-10. [CrossRef]

42. Leite, L.E.A.; Cruz, I.B.M.d.; Baptista, R.; Heidner, G.S.; Rosemberg, L.; Nogueira, G.; Closs, V.E.; Engroff, P.; Viegas, K.; Schneider, R. Comparative study of anthropometric and body composition variables, and functionality between elderly that perform regular or irregular physical activity. Rev. Bras. Geriatr. Gerontol. 2014, 17, 27-37. [CrossRef]

43. Wang, C.Y.; Yeh, C.J.; Wang, C.W.; Wang, C.F.; Lin, Y.L. The health benefits following regular ongoing exercise lifestyle in independent community-dwelling older Taiwanese adults. Australas. J. Ageing 2011, 30, 22-26. [CrossRef]

44. Steffl, M.; Bohannon, R.W.; Sontakova, L.; Tufano, J.J.; Shiells, K.; Holmerova, I. Relationship between sarcopenia and physical activity in older people: A systematic review and meta-analysis. Clin. Interv. Aging 2017, 12, 835. [CrossRef]

45. Ross, C.E.; Mirowsky, J. Neighborhood disadvantage, disorder, and health. J. Health Soc. Behav. 2001, 42, 258-276. [CrossRef]

46. Taani, M.H.; Siglinsky, E.; Kovach, C.R.; Buehring, B. Psychosocial factors associated with reduced muscle mass, strength, and function in residential care apartment complex residents. Res. Gerontol. Nurs. 2018, 11, 238-248. [CrossRef]

47. Davy, C.; Harfield, S.; McArthur, A.; Munn, Z.; Brown, A. Access to primary health care services for Indigenous peoples: A framework synthesis. Int. J. Equity Health 2016, 15, 163. [CrossRef] [PubMed]

48. Sudore, R.L.; Mehta, K.M.; Simonsick, E.M.; Harris, T.B.; Newman, A.B.; Satterfield, S.; Rosano, C.; Rooks, R.N.; Rubin, S.M.; Ayonayon, H.N. Limited literacy in older people and disparities in health and healthcare access. J. Am. Geriatr. Soc. 2006, 54, 770-776. [CrossRef] [PubMed]

49. Oliveira, D.; Bosco, A.; di Lorito, C. Is poor health literacy a risk factor for dementia in older adults? Systematic literature review of prospective cohort studies. Maturitas 2019, 124, 8-14. [CrossRef]

50. Orstad, S.L.; McDonough, M.H.; Stapleton, S.; Altincekic, C.; Troped, P.J. A Systematic Review of Agreement Between Perceived and Objective Neighborhood Environment Measures and Associations With Physical Activity Outcomes. Environ. Behav. 2016, 49, 904-932. [CrossRef]

51. Gebel, K.; Bauman, A.; Owen, N. Correlates of non-concordance between perceived and objective measures of walkability. Ann. Behav. Med. 2009, 37, 228-238. [CrossRef] [PubMed] 